\section{Jenis-Jenis Vegetasi di Area Penangkaran Burung Maleo Desa Taima Kecamatan Bualemo Kabupaten Banggai}

\author{
Wahyudin Abd. Karim \\ Abd. Muin Kenta
}

\begin{abstract}
Abstrak. Macrocephalon maleo merupakan jenis burung yang diklasifikasikan sebagai Terancam Punah oleh IUCN dan satwa prioritas untuk dilindungi oleh Pemerintah Indonesia. Penelitian dilaksanakan pada bulan April - Juli 2019, pengambilan data di Tempat Bertelur Burung Maleo (TBBM) Desa Taima, Kecamatan Bualemo, Kabupaten Banggai. Data dikumpulkan dari dua buah jalur pengamatan pada sebanyak 5 plot pengamatan, dan dianalisis frekuensi relatif distribusinya. Hasil penelitian menunjukkan bahwa terdapat 18 species tumbuhan untuk semua plot. Pada plot jenis pohon didominasi oleh Quassia indica (29.42\%), plot jenis tiang didominasi oleh Thespesia populnea (11.86\%), plot jenis pancang didominasi oleh Cycas sp. (9.81\%) dan plot jenis semak didominasi oleh Justicia sp. L (31.98\%). Hasil penelitian lain menunjukkan bahwa bahwa habitat burung maleo di kedua lokasi terdiri dari pohon-pohon dengan ketinggian yang berkisar antara 7-15 meter dan semak belukar.

Kata Kunci: vegetasi, tumbuhan, maleo, desa taima.
\end{abstract}

\section{Pendahuluan}

Sulawesi merupakan pulau keempat terbesar di Indonesia. Sulawesi terletak di antara garis Wallace dan Weber, kawasan peralihan biogeografi Australia dan Asia Whitten et al. (1987). Hal inilah yang membuat pulau Sulawesi menjadi salah satu pulau yang memiliki kekayaan flora dan fauna yang begitu beragam dan melimpah, salah satunya adalah Burung Maleo (Macrocephalon maleo).

Hutan merupakan salah satu habitat dari bermacammacam jenis burung. Secara alamiah hutan dengan berbagai jenis tumbuhan akan menyediakan sumber makanan berupa biji-bijian dan buah bagi burung yang menjadi penghuninya, akan memberikan rasa aman bagi satwa tersebut untuk bersarang dan berkembangbiak. Keanekaragaman struktur habitat berpengaruh pada keanekaragaman jenis burung. Struktur hutan memberikan pengaruh nyata terhadap burung yang tinggal di dalam habitat tersebut (Sayogo, 2009). Penangkaran atau Tempat Bertelur Burung maelo (TBBM) yang terletak di Dusun Tamparang Desa Taima Kecamatan Bualemo ini masih berstatus HPL (Hak Pengelolaan Lahan). Lahan yang berlokasi di Dusun Tamparang ini milik warga setempat dan dibeli oleh Organisasi Aliansi Konservasi Tompotika (AlTo). Luas Wilayah penangkaran

\section{BIONATURE}

p-ISSN 1411 - 4720

e-ISSN 2654 - 5160

Abstract. Macrocephalon maleo an endemic bird species to Sulawesi and classified as Endangered by the IUCN and on the Government of Indonesia's list of priority species for conservation. The study was conducted in April - July 2019,

data collection was taken from nesting ground of the maleo bird in Taima Village, sub district Bualemo, districs Banggai. Data were collected from two transects on 5 plots, and were analysed its relative frequency distribution. The results showed that there were 18 plant species for all plots. In tree species plots are dominated by Quassia indica $(29.42 \%)$ pole type plots are dominated by

Thespesia populnea (11.86\%), sapling plots are dominated by Cycas sp. (9.81\%) and bush species plots were dominated

by Justicia sp. L (31.98\%). The results others showed that habitat Maleo at both

locations consisted of trees with 7-15 meters tall and shrubs.

Keywords: vegetation, plant, maleo, taima village.

Wahyudin Abd. Karim
Universitas Muhammdiyah Luwuk
Indonesia

Abd. Muin Kenta

Universitas Muhammdiyah Luwuk Indonesia 
\pm 40 Ha dengan dengan titik koordinat $00^{\circ} 37^{\prime} 54.0^{\prime \prime} \mathrm{S}, 123^{\circ} 21^{\prime} 149^{\prime \prime}$ E. Burung maleo tergolong jenis satwa liar langka yang dilindungi di Indonesia berdasarkan SK Mentan No. 421/Kpts/UM/8/1970 dan SK Mentan No. 90/Kpts/UM/2/1977. Jenis ini juga dilindungi berdasarkan UU RI No. 5 Tahun 1990 tentang Konservasi Sumberdaya Alam Hayati dan Ekosistemnya, SK Menhut No. 301/Kpts-II/1991 dan No. 882/Kpts-II/1992 serta PP No. 7 tahun 1999 tentang Pengawetan Jenis Tumbuhan dan Satwa (Laban, 2007). Komponen habitat yang terpenting bagi maleo adalah habitat penelurannya karena maleo tidak mengerami sendiri telurnya melainkan memendamnya di dalam tanah/pasir pada kedalaman tertentu. Keberadaan sarang maleo yang semakin berkurang diduga sangat dipengaruhi oleh rusaknya kondisi dan banyak hilangnya habitat peneluran yang sesuai untuk melakukan regenerasi (Nafiu, dkk 2015).

\section{Metode Penelitian}

Penelitian dilaksanakan di Penangkaran atau Tempat Bertelur Burung Maleo (TBBM) yang terletak di Dusun Tamparang Desa Taima Kecamatan Bualemo Kabupaten Banggai pada bulan April - Juli 2019. Penelitian ini melihat jenis vegetasi di Area sekitar di Penangkaran atau Tempat Bertelur Burung Maleo (TBBM).

\section{Alat dan Bahan}

Alat dan bahan yang digunakan pada penelitian ini ialah peta Kawasan, Global Position Sistem (GPS), gunting stek, alat tulis, kamera digital, tally sheet, alkohol, sasak dan koran bekas.

\section{Pengamatan Vegetasi}

Untuk mengetahui jenis vegetasi dilakukan pembuatan plot pengamatan di lokasi penelitian menggunakan metode petak ganda pengambilan titik (purposive sampling) dan garis transek di sekitar tempat burung maleo. Pengamatan dan pengukuran karakteristik habitat yaitu temperatur, kelembaban, diameter, dan kedalaman pada lubang peneluran burung maleo di habitat alami.

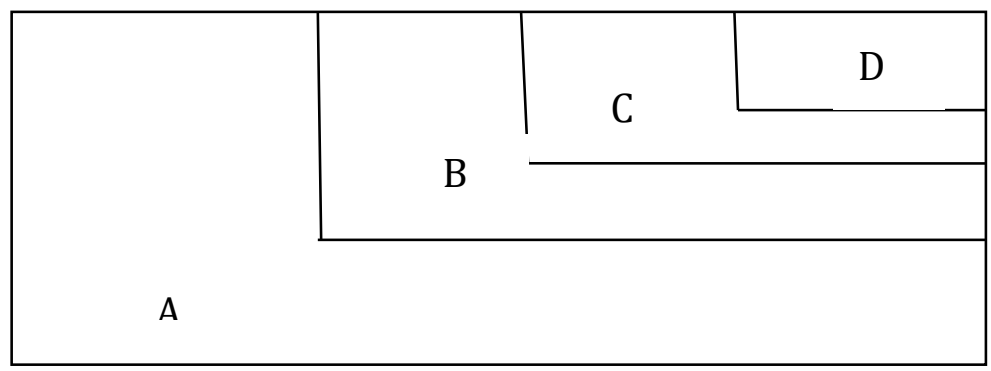

\section{Gambar 1. Plot Pengamatan di Lokasi Penelitian Menggunakan Metode Petak Ganda Pengambilan Titik (Purposive Sampling) dan Garis Transek di Sekitar Tempat Burung Maleo}

\section{Keterangan:}

A. Plot pengamatan tingkat pohon (plot $20 \times 20 \mathrm{~m}$ )

B. Plot pengamatan tingkat tiang (plot $10 \times 10 \mathrm{~m}$ )

C. Plot pengamatan tingkat pancang (plot ukuran $5 \times 5 \mathrm{~m}$ )

D. Plot pengamatan tingkat semai (plot ukuran $2 \times 2 \mathrm{~m}$ ) 
Jenis-Jenis Vegetasi di Area Penangkaran Burung Maleo Desa

Taima Kecamatan Bualemo Kabupaten Banggai

(hlm. 84-88)

\section{Analisis Data}

Untuk mengetahui komposisi dan struktur vegetasi pada level tiang dan pohon, data dianalisis dengan menghitung kerapatan relatif (KR), frekuensi relatif (FR), dominansi relatif (DR) dan indeks nilai penting (INP) dengan menggunaan rumus menurut (Kusmana, 1997).

$$
\begin{gathered}
\frac{\text { Jumlah Individu (JenisTumbuhan) }}{\text { Luas Petak Contoh }} \\
\mathrm{F}=\frac{\text { Jumlah Petak ditemukan Suatu Jenis }}{\text { Jumlah Seluruh Petak Contoh }} \\
\mathrm{D}=\frac{\text { Luas Bidang Dasar Suatu Jenis }(\mathrm{m} 2)}{\text { Luas Seluruh Petak Contoh }(\text { ha })} \\
\mathrm{KR}=\frac{\text { Kerapa } \tan \text { Suatu Jenis }}{\text { Kerapa } \tan \text { Total Seluruh Jenis }} \times 100 \% \\
\mathrm{FR}=\frac{\text { Frekuensi Suatu Jenis }}{\text { Frekuensi Seluruh Jenis }} \times 100 \% \\
\text { DR }=\frac{\text { Domansi Suatu Jenis }}{\text { Domansi Seluruh Jenis }} \times 100 \%
\end{gathered}
$$

Indeks Nilai Penting (INP) dihitung dengan menggunakan rumus: $I N P=K R+F R+D R$

\section{Hasil Penelitian}

Jenis Vegetasi di Penangkaran atau Tempat Bertelur Burung Maleo (TBBM)

Tabel 1. Nilai Indeks Nilai Penting Metode Petak Ganda

\begin{tabular}{|c|l|c|c|c|c|}
\hline No & \multicolumn{1}{|c|}{ Kategori Jenis Pohon } & KR & FR & DR & INP \\
\hline \multicolumn{5}{|c|}{} \\
\hline 1 & Aglaia tomentosa Teijsm. \& Binn & 0,09 & 3,51 & 11,09 & 14,69 \\
\hline 2 & Calophyllum inophyllum L. & 0,32 & 7,02 & 10,08 & 17,43 \\
\hline 3 & Canarium sp. & 0,11 & 5,26 & 6,34 & 11,71 \\
\hline 4 & Palaquium sp. & 0,20 & 7,02 & 6,63 & 13,84 \\
\hline 5 & Psycothria sp. & 0,14 & 7,02 & 8,64 & 15,80 \\
\hline 6 & Quassia Indica & 0,01 & 1,75 & 27,66 & 29,42 \\
\hline 7 & Terminalia Catappa & 0,01 & 1,75 & 18,44 & 20,21 \\
\hline \multicolumn{5}{|c|}{ Jenis Tiang } \\
\hline 1 & Thespesia populnea (L.) Sol. ex Corrêa & 0,80 & 7,02 & 4,04 & 11,86 \\
\hline 2 & Urophyllum sp. & 0,75 & 5,26 & 3,03 & 9,04 \\
\hline 3 & Callicarpa glabrifolia S.Atkins & 0,50 & 7,02 & 4,04 & 11,56 \\
\hline
\end{tabular}




\begin{tabular}{|c|l|c|c|c|}
\hline \multicolumn{5}{|c|}{ Jenis Pancang } \\
\hline 1 & Calotropis gigantea (L.) W.T.Aiton & 2,20 & 5,26 & 7,46 \\
\hline 2 & Cycas sp. & 2,80 & 7,02 & 9,81 \\
\hline 3 & Leucaena leucocephala (Lam.) de Wit & 2,20 & 5,26 & 7,46 \\
\hline \multicolumn{4}{|c|}{ Jenis Semak } \\
\hline 1 & Staurogyne sp. & 16,23 & 5,26 & 21,49 \\
\hline 2 & Ruellia tuberosa L. & 22,47 & 7,02 & 29,49 \\
\hline 3 & Justicia sp. & 24,97 & 7,02 & 31,98 \\
\hline 4 & Flueggea virosa (Roxb. ex Willd.) Royle & 11,23 & 5,26 & 16,50 \\
\hline 5 & Capparis sp. & 14,98 & 5,26 & 20,24 \\
\hline
\end{tabular}

Tabel 2. Nilai Indeks Nilai Penting Metode Garis Transek

\begin{tabular}{|c|l|c|c|c|c|c|}
\hline No & \multicolumn{1}{|c|}{ Nama Tumbuhan } & F & FR & K & KR & INP \\
\hline 1 & Aglaia tomentosa Teijsm. \& Binn & 0,4 & 4,08 & 0,02 & 0,99 & 5,07 \\
\hline 2 & Ardisia sp. & 1 & 10,20 & 0,15 & 7,39 & 17,59 \\
\hline 3 & Calotropis gigantea (L.) W.T.Aiton & 0,4 & 4,08 & 0,08 & 3,94 & 8,02 \\
\hline 4 & Canthium sp. & 0,6 & 6,12 & 0,15 & 7,39 & 13,51 \\
\hline 5 & Capparis sp. & 0,4 & 4,08 & 0,04 & 1,97 & 6,05 \\
\hline 6 & Chromolaena odorata (L.) R.M.King \& H.Rob. & 1 & 10,20 & 0,24 & 11,82 & 22,03 \\
\hline 7 & Cycas sp. & 0,2 & 2,04 & 0,02 & 0,99 & 3,03 \\
\hline 8 & Flueggea virosa (Roxb. ex Willd.) Royle & 1 & 10,20 & 0,22 & 10,84 & 21,04 \\
\hline 9 & Grewia multiflora Juss. & 0,4 & 4,08 & 0,02 & 0,99 & 5,07 \\
\hline 10 & Justicia sp. & 1 & 10,20 & 0,23 & 11,33 & 21,53 \\
\hline 11 & Leucaena leucocephala (Lam.) de Wit & 0,2 & 2,04 & 0,03 & 1,48 & 3,52 \\
\hline 12 & Ocimum basilicum L. & 1 & 10,20 & 0,27 & 13,30 & 23,50 \\
\hline 13 & Ruellia tuberosa L. & 1 & 10,20 & 0,3 & 14,78 & 24,98 \\
\hline 14 & Staurogyne sp. & 1 & 10,20 & 0,25 & 12,32 & 22,52 \\
\hline 15 & Callicarpa glabrifolia S.Atkins & 0,2 & 2,04 & 0,01 & 0,49 & 2,53 \\
\hline
\end{tabular}

\section{Pembahasan}

\section{Struktur dan Komposisi Tumbuhan}

Dari hasil perhitungan Indeks Nilai Penting (INP) pada tumbuhan di Penangkaran atau Tempat Bertelur Burung Maleo (TBBM) yang terletak di Dusun Tamparang Desa Taima Kecamatan Bualemo, telah di temukan 18 jenis untuk metode Plot Petak Ganda dengan Indeks Nilai Penting tertinggi pada Quassia indica (29.42\%), plot jenis tiang didominasi oleh Thespesia populnea (11.86\%), plot jenis pancang didominasi oleh Cycas sp. (9.81\%) dan plot jenis semak didominasi oleh Justicia sp. $L$ (31.98\%). Sedangkan untuk metode Garis Transek di temukan 15 jenis dengan Indeks Nilai Penting tertinggi pada Ruellia tuberosa L. $(24,98 \%)$ dan terendah Callicarpa glabrifolia (2.53 \%). Nilai INP tertinggi ini berdasarkan perhitungan parameter Kerapatan Relatif (KR), Frekuensi Relatif (FR), dan Dominansi Relatif (DR).

\section{Indeks Nilai Penting}

Berdasarkan ketiga ukuran relatif yang diperoleh, dapat ditentukan Indeks Nilai Penting untuk tiap-tiap jenis dengan menjumlahkan ukuran relatif tersebut. INP suatu jenis dalam suatu komunitas tumbuhan menunjukan tingkat kepentingan atau peranan jenis tersebut dalam komunitasnya. Jenis yang memiliki nilai INP tertinggi merupakan jenis yang dominan dan memiliki peranan yang besar dalam komunitasnya. Hal ini menunjukan bahwa jenis-jenis tersebut dominan pada tingkat pertumbuhan di satu kawasan. 
Jenis-Jenis Vegetasi di Area Penangkaran Burung Maleo Desa

Taima Kecamatan Bualemo Kabupaten Banggai

(hlm. 84-88)

\section{Kesimpulan}

Dari hasil penelitian yang dilakukan di Penangkaran atau Tempat Bertelur Burung Maleo (TBBM) yang terletak di Dusun Tamparang Desa Taima Kecamatan Bualemo Kabupaten Banggai ditemukan 18 jenis untuk metode Plot Petak Ganda dengan Indeks Nilai Penting tertinggi pada Quassia indica (29.42\%), plot jenis tiang didominasi oleh Thespesia populnea $(11.86 \%)$, plot jenis pancang didominasi oleh Cycas sp. (9.81\%) dan plot jenis semak didominasi oleh Justicia sp. L (31.98\%). Sedangkan untuk metode Garis Transek di temukan 15 jenis dengan Indeks Nilai Penting tertinggi pada Ruellia tuberosa L. $(24,98 \%)$ dan terendah Callicarpa glabrifolia (2.53\%).

\section{Referensi}

Butchart, S.H.M \& Gillian C. Baker. (1998). Priority Sites for Conservation of Maleo (Macrocephalon maleo) in Central Sulawesi. Department of Zoology, Downing Street, Cambridge, CB2 3 EJ, UK. 20p.

Butchart, S.H.M \& Gillian C. Baker. (2000). Priority sites for conservation of maleos (Macrocephalon maleo) in central Sulawesi. Biological Conservation, 9, 79-91.

Laban, L. M. (2007). Pendugaan Populasi, Preferensi Habitat Peneluran dan Pola Sebaran Maleo (Macrocephalon maleo Sal Muller 1846) Berdasarkan keberadaan Sarang di Kawasan Taman Nasional Lore Lindu Kabupaten Donggala Propinsi Sulawesi Tengah. Skripsi. Departemen Konservasi Sumberdaya Hutan dan Ekowisata Fakultas Kehutanan Institut Pertanian Bogor.

Nafiu L.O, Rusdin M, Saili T, \& Nurhalim. (2015). Karateristik Habitat Maleo (Macrocephalon maleo SAL MULER 1846) di Taman Nasional Rawa Aopa Watumohai (TNRAW). Jitro, 2 (1), $1-13$.

Silayar, R, Hard N. Pollo, Johny S. Tasirin. (2018). Struktur dan Komposisi Pohon di Habitat Burung Maleo (Macrocephalon maleo S. Muller, 1846). Cocos, 1(2), 1-7.

Sayogo, A.P. (2009). Keanekaragaman Jenis Burung pada Beberapa Tipe Habitat di Taman Nasional Lore Lore Lindu Provinsi Sulawesi Tengah. Skripsi. Fakultas Kehutanan Institut Pertanian Bogor.

Samana, J.Y. (2015). Estimasi Populasi dan Karakteristik Fisik Burung Maleo (Macrophalon Maleo) di Resort Saluki Desa Tuva Kawasan Taman Nasional Lore Lindu (TNLL). EJournal Geo- Tadulako, 4 (1), 1-21.

Whitten, A.J, Mustafa M, Henderson G.S. (1987). The Ecology of Sulawesi. Yogyakarta. Indonesia. Gadja University Press, 777pp.

\begin{tabular}{|l|l|}
\hline Wahyudin Abd. Karim & $\begin{array}{l}\text { Universitas Muhammdiyah Luwuk } \\
\text { E-mail: } \underline{\text { wahyudinabdulkarim87@gmail.com }}\end{array}$ \\
\hline Abd. Muin Kenta & $\begin{array}{l}\text { Universitas Muhammdiyah Luwuk } \\
\text { E-mail: wahyudinabdulkarim87@gmail.com }\end{array}$ \\
\hline
\end{tabular}

